\title{
Reseña de La Bhagavad-Gītā. El clásico de la literatura sánscrita y su recepción
}

\author{
Dr. Roberto E. García ${ }^{1}$ \\ Universidad del Claustro de Sor Juana, México
}

\section{Reseña de Libro}

Figueroa, Ó.[Coord.].(2017). La Bhagavad-Gītā. El clásico de la literatura sánscrita y su recepción. México: Universidad Nacional Autónoma de México, Centro Regional De Investigaciones Multidisciplinarias, Juan Pablos Editor. ISBN:978-607-02-8892-0, 338 pp.

Material original autorizado para su primera publicación en el Journal de Ciencias Sociales, Revista Académica de la Facultad de Ciencias Sociales de la Universidad de Palermo.

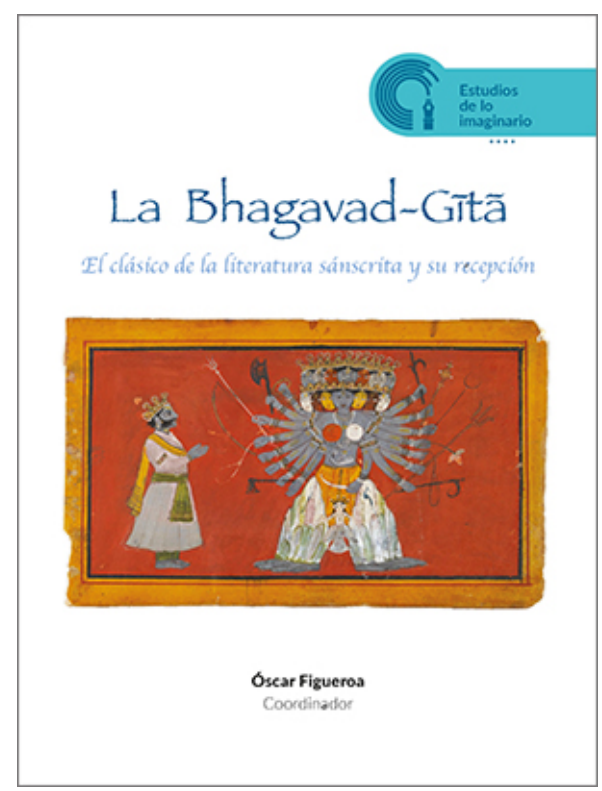

La Bhagavadgītā es quizála obra literaria hinduista más conocida y comentada tanto en círculos académicos como entre el público no especializado. Desde la traducción de Charles Wilkins al inglés en 1785, la Bhagavadgītāha sido objeto de un número colosal de traducciones, comentarios y estudios. El libro de Jagdish Kapoor, Bhagavad-Gītā: An International Bibliography of 1785-1979 Imprints, publicado en 1983, enlista más de 2700 referencias bibliográficas en lenguas europeas e indias relacionadas con esta obra. Es muy probable que el número de obras producidas en los dos siglos que abarca Kapoor sea mayor, y es un hecho innegable que el interés académico y popular con respecto a la Bhagavadgitāestá muy lejos de haberse agotado en las últimas décadas. Esto es cierto también para el mundo de habla hispana. Apenas el año pasado vio la luz una nueva

\footnotetext{
${ }^{1}$ Doctor en Estudios Budistas. Universidad del Claustro de Sor Juana.
} 
traducción, a cargo de Juan Arnau, que se une a la nutrida lista de versionesen español de la Bhagavadgītā, directas e indirectas, producidas para satisfacer distintos tipos de público.

El libro de ensayos La Bhagavad-Gïtā. El clásico de la literatura sánscrita y su recepción, coordinado por Óscar Figueroa, se suma a la larga tradición de estudios académicos sobre la Bhagavadgītā. Está compuesto por catorce trabajos de investigadores de distintas nacionalidades, de los cuales todos menos dos fueron escritos en lengua castellana, diez de ellos especialmente para este libro. Tal como el título lo indica, el objeto de estudio de esta compilación de textos es la Bhagavadgītā. Pero lejos de limitarse a esta obra clásica, una buena parte de los ensayos se encarga de estudiar las recepciones e interpretaciones de la Bhagavadgītāen múltiples contextos, abarcando épocas históricas y ámbitos ideológicos muy distintos, como lo son la India antigua, representada por distintos comentaristas, y algunos países latinoamericanos de la época moderna.

En la Introducción a la obra se plantean claramente dos objetivos principales. El primero consiste en ofrecer al lector de habla hispana una especie de guía que lo lleve a conocer distintas facetasde la Bhagavadgītā, abarcando muy diversos temas y campos del conocimiento. El segundo objetivo del volumen es servir como una introducción general, pero selecta, a la Bhagavadgittā, estableciendo el énfasis en la capacidad que ha mostrado esta obra paraajustarse a distintos contextos de interpretación, apropiación y reutilización. En suma, se pretende señala que la Bhagavadgītā, lejos de ser una obra monolítica y fija, ha demostrado ser un artefacto cultural altamente productivo que ha experimentado diversas resignificaciones y lecturas, cada una con sus propiasmotivaciones y agendas religiosas, sectarias, políticas o ideológicas.

Es posible afirmar que este libro logra cabalmente sus objetivos en más de un sentido. Por una parte introduce al lector a los temas centrales de la obra, así como a ciertas discusiones relevantes sobre su composición y estructura interna. Por otra parte, la labor de los investigadores que contribuyeron a este volumen demuestra que la Bhagavadgittā ha cobrado importancia en distintas épocas y ámbitos intelectuales gracias, en buena medida, a la multiplicidad de lecturas e interpretaciones que ha suscitado y no debido a que posea alguna esencia inmutable inherente que vuelve a resurgir en cada época. Finalmente, el volumen en sí mismo es un caso sobresaliente de recepción de la Bhagavadgītā, en este caso dentro del ámbito de la indología en lengua castellana. Los ensayos que conforman esta compilación, además de representar un conjunto sobresaliente deerudición, han tomado a la Bhagavadgïtācomo un motivo para desarrollar algunos de los intereses principales que atraviesan a este segmento de los estudios indológicos contemporáneos.

La obra está dividida en cuatro grandes secciones, cada una de las cuales representa una postura de análisis con respecto a la Bhagavadgītā. Los cinco ensayos de la 
primera, "Historia textual y doctrinas", estudian la obra a partir de su composición, estructura y contenido. El trabajo de Wendy Phillips aborda la obra desde la perspectiva de la crítica e historia del texto; Luis González Reimann analiza la interpretación doctrinal del tiempo en relación con la figura de Krṣna; Ana Agud estudia el papel de la obra dentro del marco narrativo del Mahābhārata; por su parte, Juan Arnau investiga las relaciones de la filosofía Sānkhya con la Bhagavadgĩtā; y finalmente Olivia Cattedra analiza dos discursos centrales en la obra: el renacimiento y la liberación final.

En la segunda sección, "Recepciones tradicionales", cuatro ensayos estudian la Bhagavadgītā como objeto de interpretación de exégetas indios de distintas tradiciones, poniendo de relieve que laobra, lejos de haberse considerado como un texto cerrado y definitivo en contextos tradicionales de la India antigua, estaba abierta en todo momento a la resignificación. Los trabajos de Javier Ruiz Calderón yÒscar Pujol se centran en el Advaitavedānta; el primero estudia la interpretación de la Bhagavadgītāen distintos pensadores de esta tradición, incluyendo a Śańkara, mientras que el segundo ofrece argumentos filológicos para sostener que este filósofo es el auténtico autordel Bhagavadgītābhāșya, tal como la tradición lo sostiene. Refiriéndose a contextos doctrinales muy distintos, el ensayo de Óscar Figueroa analiza la interpretación esotérica de la Bhagavadgītāpor parte del filósofo tántrico Abhinavagupta en su comentario titulado Gittārthasañgraha y en otras obras, mientras que Elsa Crossestudia la exégesis de la obra a cargo del místico y devoto Jñāneśvar en su Bhāvārthadīpikā.

Los tres trabajos de la tercera sección, "Recepciones Modernas", se enfocan en la recepción del texto en la época moderna, específicamente en tres contextos latinoamericanos. Los ensayos de Armando García de la Torrey de José Ricardo Chaves son una contribución extraordinaria al estudio del orientalismo americano y de su relación con el pensamiento político y lasluchas de independencia y revolución en Latinoamérica; el primero aborda el caso de José Martí, mientras que el segundo se enfoca en Francisco I. Madero y sus versiones de la Bhagavadgītā. Finalmente, Lía Rodriguez de la Vega estudia las interpretaciones de la obra en el contexto contemporáneo de una familia de inmigrantes indios en la ciudad de Buenos Aires.

La última sección, "Alcances Teóricos y Comparativos", cierra el volumen con dos ensayos que abordan la Bhagavadgītādesde perspectivas distintas. El trabajo de Herbert Fingarette investiga algunos postulados de la obra por medio de un ejercicio de reflexión filosófica. Por su parte, el ensayo de Adrián Muñoz presenta un análisis comparativo de la Bhagavadgītāy el Libro de Job a partir de sus respectivas estructuras narrativas y temáticas comunes.

Como parte de las contribuciones de este volumen al estudio de la Bhagavadgitāy a los estudios indológicos en lengua castellana, cabe señalar el "Apéndice II. Ediciones y 
traducciones de la Bhagavadgītā", a cargo de Óscar Figueroa. Se trata de un breve estudio bibliográfico que da cuenta de las principales ediciones de la obra sánscrita y de las traducciones a lenguas europeas. Destaca el apartado "Traducciones al Español", que ofrece una investigación bien informada sobre las primeras traducciones al español y traza una genealogía de las versiones más importantes en esta lengua.

Considero que esta compilación de ensayos es original en varios aspectos. Es una aportación valiosa y significativa al ámbito de los estudios de India en los países de habla hispana y aporta contribuciones de calidada diversas áreas del conocimiento, como por ejemplo a los estudios de crítica textual, historia literaria, filología clásica, orientalismo, historia de Latinoamérica, literatura comparada y filosofía aplicada al pensamiento religioso, entre otros.Como obra colectiva representa un valioso ejercicio de pluralidad académica, en tanto que abordael estudio de la Bhagavadgītādesde distintas perspectivas, teorías y metodologías, ofreciendo así al lector la posibilidad de entenderla obra desde su complejidad multifacética.

No cabe dudade que el público especializado será el que saque el mayor provecho de esta publicación, pues le permitirá ampliar sus conocimientos sobre diversas capas de la historia de la recepción de la Bhagavadgītā.Sin embargo, a pesar de que este volumen no es un trabajo de divulgación general, considero que la diversidad de temas y enfoques que presenta lo convierte también en un medio excelente paraintroducir a la obra al lector no especializado que esté interesado en estudiar aspectos complejos de este texto clásico. 